\title{
Water descent: A simple, effective technique for avoidance learning in hamsters
}

\author{
M. ANDREW DuBOIS and KENNETH B. MELVIN \\ University of Alabama, Tuscaloosa, Alabama 35486
}

Within 50 acquisition trials, four male and four female hamsters learned to avoid falling into a container of water by exiting a startbox within $10 \mathrm{sec}$ of the onset of a compound stimulus composed of an auditory (buzzer) and a visual (light) element. During $30 \mathrm{CS}$ effectiveness trials, four animals were assigned to a group receiving either the auditory or the visual stimulus. Finally, 30 extinction trials were given. The water descent led to quick and effective avoidance learning, and the auditory cue was the more potent stimulus in avoidance performance. Extinction gradually occurred.

Research on avoidance learning in the golden hamsters has been somewhat limited. Several studies investigating shock avoidance learning in these animals (e.g., Ewing, 1964; Williams, 1963) have met with marginal success in producing avoidance responding with the hamster. Studies by Babbini and Davis (1967) and Lin and Mogenson (1968) suggest that avoidance learning in several species of rodents, including the hamster, is directly related to the experimental procedure used, as well as the nature of the avoidance response. Further, interspecies differences appear asystematically and are not obviously a result of species-specific deficits in learning ability.

The present study was an attempt to determine the effectiveness of a water-descent UCS in producing avoidance responding in the hamster, and further, to assess differential responses to the auditory and visual components of the CS.

\section{METHOD}

Subjects and Apparatus

Subjects were four male and four female Syrian golden hamsters purchased from a local supplier. All subjects were 90110 days old and were caged in sexually homogeneous pairs with food and water available ad lib.

The apparatus consisted of a 12 in. long $\times 12$ in. wide $\times 8$ in. high $(30.5 \times 30.5 \times 20 \mathrm{~cm})$ plywood box with a manually operated trapdoor floor. A $4.7-\mathrm{kHz}$ piezoelectric solid state Radio Shack buzzer and a 6-V white flashlight-type bulb were affixed to one wall. The opposite double wall was drilled to accommodate a $2-\mathrm{ft}(61-\mathrm{cm})$ horizontal transparent yellow tube that provided an exit from the box. The tube was centered and .5 in. $(1.3 \mathrm{~cm})$ off the floor. A guillotine-type plywood door situated between these double walls was operated manually to initiate two trials. All electrical components were powered by an Eveready 6-V battery. The entire apparatus stood on three legs and was placed inside a 6 -in.- $(15-\mathrm{cm}-)$ deep square plastic container that had been filled with warm tap water $\left(80^{\circ} \mathrm{F}\right.$ $\pm 5^{\circ} \mathrm{F}$ ), with the trapdoor floor $8 \mathrm{in}$. $(20 \mathrm{~cm})$ from the surface of the water.

Requests for reprints should be sent to Kenneth B. Melvin, Department of Psychology, University of Alabama, University, Alabama 35486.

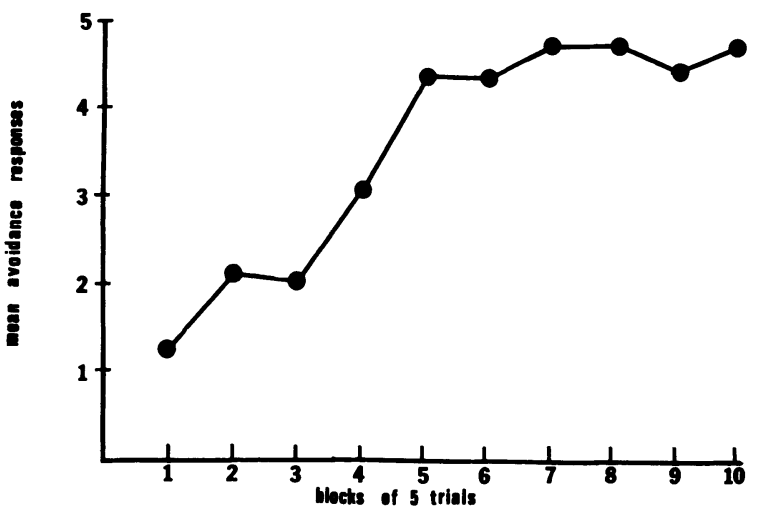

Figure 1. Mean number of avoidance responses across 10 blocks of five acquisition trials.

Procedure

Acquisition. Each subject was placed in the startbox and given $30-45 \mathrm{sec}$ to explore the apparatus. The subject was then presented the auditory (buzzer) and visual (light) CSs for $10 \mathrm{sec}$. At the onset of the CS, the guillotine-type door was lifted, allowing the subject to enter the tube. At the end of $10 \mathrm{sec}$, the trapdoor floor was released, allowing the subject to fall into the water, provided it had not left the box. All subjects were given 50 acquisition trials. The intertrial interval ranged from 40 to $60 \mathrm{sec}$.

CS effectiveness. For this 30 -trial sequence, the subjects were randomly divided into two groups, with the restriction that two males and two females be in each group. Group A received only the auditory stimulus (buzzer), and Group V received only the visual stimulus (light). All other procedures were the same as in the acquisition sequence.

Extinction. During these 30 extinction trials, the same conditions were used, except that the subjects were never dropped into the water. If the subject did not avoid within $10 \mathrm{sec}$, the door was closed and the next trial was given in $45-60$ sec.

\section{RESULTS}

\section{Acquisition}

All subjects learned the avoidance response. Analysis of variance across all 10 blocks of acquisition trials reveals a significant blocks effect $[F(8,70)=9.97$, 


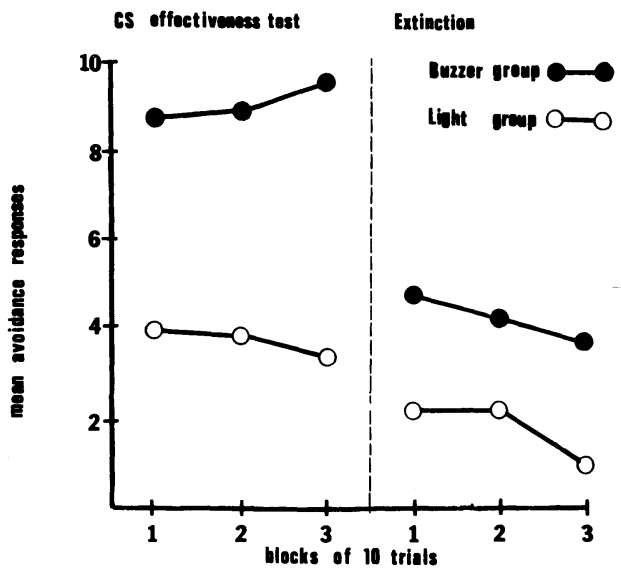

Figure 2. Mean number of avoidance responses across three blocks of 10 trials during the CS effectiveness test and subsequently the extinction phase.

$\mathrm{p}<.01$ ] . Figure 1 represents mean avoidance responses for each group across the 10 blocks of five acquisition trials.

\section{CS Effectiveness Test}

Figure 2 shows the mean number of avoidance responses for the auditory (A) and visual (V) stimulus groups during continued avoidance. Analysis of variance supported the primacy of the auditory stimulus, revealing a significant groups effect $[F(1,6)=69.63$, $p<.001$ ] , but no effect of blocks of trials.

\section{Extinction}

Mean number of avoidance responses for the two groups were compared over three blocks of 10 trials (see Figure 2). Only the blocks effect was significant, indicating that both groups exhibited the standard extinction effect $[\mathrm{F}(2,12)=4.67, \mathrm{p}<.05]$.

\section{DISCUSSION}

Results in this study clearly show that a water descent is quite effective in producing avoidance learning and extinction in hamsters. Results also show that an auditory cue is the more potent stimulus of the two in triggering avoidance. This finding is also congruent with the results of Babbini and Davis (1967).

Given the difficulty with shock avoidance in hamsters, the water-descent technique appears to have two major advantages: (1) It is highly effective, and (2) it is simple to implement. One could easily adapt it to the general experimental laboratory. Furthermore, the technique could be used with a variety of species, excepting, of course, the fish and its ilk. In fact, the water descent served well as a UCS for the rat in a study of allsecondary vicious-circle behavior (Melvin, Irving, \& PrenticeDunn, 1979).

\section{REFERENCES}

Babbini, M., \& Davis, W. M. Active avoidance learning in hamsters. Psychonomic Science, 1967, 9, 149-150.

EwING, D. R. Avoidance conditioning in two varieties of the Syrian hamster. Unpublished master's thesis, Iowa State University, 1964.

Lin, J., \& Mogenson, G. J. Avoidance learning in the guinea pig, hamster, and rat. Psychological Reports, 1968, 22, 431439.

Melvin, K. B., Irving, T. K., \& Prentice-Dunn, S. Fearmotivated vicious-circle behavior maintained through secondary punishment. Animal Learning \& Behavior, 1979, 7, 185-190.

Williams, R. E. A comparative study of golden hamsters and albino rats in an avoidance conditioning situation. Unpublished master's thesis, Iowa State University, 1963.

(Received for publication August 20, 1982.) 